\title{
6 Crença de Autoeficácia para Prática de Atividade Física e Variáveis de Contexto de uma Escola Pública Paulista
}

\author{
Roberto Tadeu laochite ${ }^{1}$ \\ Roraima Alves da Costa Filho²
}

\section{Introdução}

Este estudo é parte integrante de um projeto de formação inicial de professores, amparado pelo Programa PIBID/CAPES. Trata-se de um projeto cujo foco está centrado na formação de futuros professores de educação física para ensinar hábitos saudáveis na escola. $\mathrm{O}$ texto a seguir apresenta as justificativas que levaram à proposição da temática do projeto, bem como os resultados de um dos vários estudos em desenvolvimento, derivados da realização deste projeto. A discussão dos resultados se apoia no referencial da teoria social cognitiva, em especial, no constructo da autoeficácia para a prática de atividade física. Ao final, é possível encontrar considerações e encaminhamentos que tomam por base os postulados da teoria social cognitiva e o fenômeno da promoção de hábitos saudáveis na escola.

Dados recentes apontam que a prevalência de obesidade infantil tem crescido rapidamente. Matsudo et al. (2016), por exemplo, encontraram que apenas $44,1 \%$ de um total de 485 crianças entre 9 a 11 anos atingiram o mínimo recomendado de atividade física

Apoio

${ }^{1}$ PIBID/CAPES $\# 61 / 2013$

${ }^{2}$ FAPESP moderada/vigorosa em São Caetano do Sul, SP; 45,4\% apresentaram sobrepeso/obesidade calculado através do índice de massa corporal (IMC), e outros 33\% apresentam elevado índice de gordura corporal. Outros estudos também têm encontrado um cenário desafiador. Comparado a 30 anos atrás, hoje as crianças apresentam maiores níveis de gordura corporal (FERRARI et al., 2013a) e menor 
Autoeficácia em Contextos de Saúde, Educação e Política

Roberto Tadeu laochite \& Roberta Gurgel Azzi

Organizadores

para continuar lendo, clique aqui 